\title{
Crustose coralline algae can suppress macroalgal growth and recruitment on Hawaiian coral reefs
}

\author{
M. J. A. Vermeij ${ }^{1,2,3, *}$, M. L. Dailer ${ }^{1}$, C. M. Smith ${ }^{1}$ \\ ${ }^{1}$ Department of Botany, University of Hawai'i, 3190 Maile Way, St. John 101, Honolulu, Hawaii 96822, USA \\ ${ }^{2}$ CARMABI, Piscaderabaai z/n, PO Box 2090, Willemstad, Curaçao, Netherlands Antilles \\ ${ }^{3}$ Aquatic Microbiology, Institute for Biodiversity and Ecosystem Dynamics, University of Amsterdam, \\ Nieuwe Achtergracht 127, 1018 WS Amsterdam, The Netherlands
}

\begin{abstract}
Crustose coralline algae are important components of tropical reef communities because they promote successful settlement by corals and contribute to solidification of the reef framework. We show experimentally that crustose coralline algae are also capable of suppressing the growth and recruitment potential of an abundant Hawaiian reef macroalga, Ulva fasciata. When mixed communities of crustose coralline algae were absent, relative growth rates of $U$. fasciata increased by $54.6 \%$. When experimental nutrient additions were used to induce algal spore release, effective recruitment of $U$. fasciata approached zero only when crustose coralline algae were present. Mixed communities of crustose coralline algae are thus capable of limiting the local abundance of already-established macroalgae by reducing both their growth rate and recruitment success. This experimental observation was confirmed by field surveys. Because crustose coralline species also induce settlement and metamorphosis in a large number of scleractinian coral species, their abundance and species composition are expected to affect the (future) abundance of macroalgae and corals, which are often used to characterize degraded and 'healthy' reefs, respectively.
\end{abstract}

KEY WORDS: Ulva fasciata · Crustose coralline algae · CCA $\cdot$ Rhodophyta $\cdot$ Hawaii $\cdot$ Recruitment $\cdot$ Allelopathy $\cdot$ Phase shift

Resale or republication not permitted without written consent of the publisher

\section{INTRODUCTION}

Much of the current debate over processes structuring coral reef communities focuses on factors responsible for the increased abundance of fleshy or macro-

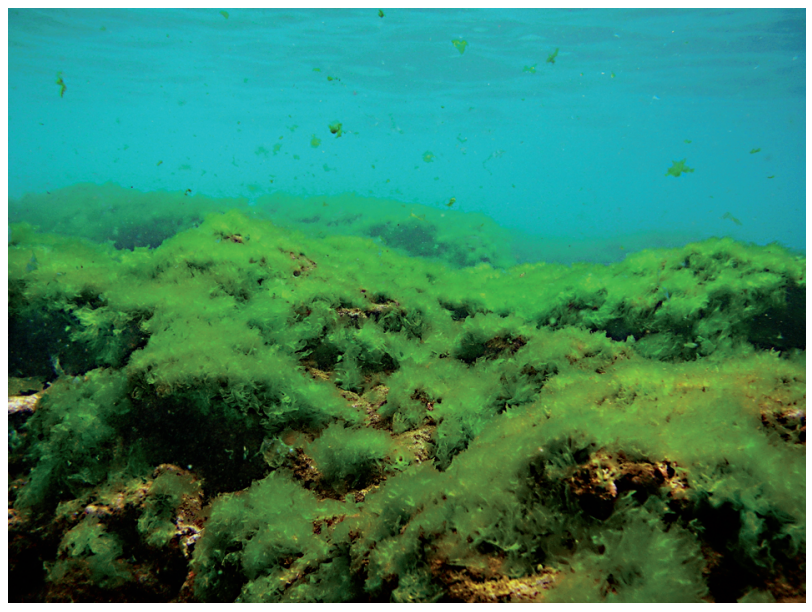

Bloom of Ulva sp. on a shallow water reef in Hawaii; germination of Ulva spores is inhibited by crustose coralline algae in a laboratory setting.

Image: Mark Vermeij

algae on reefs formerly dominated by frameworkbuilding corals (Scleractinia). Two factors are thought to be primarily responsible for increases in algal abundance on reefs: reduced predation by herbivorous invertebrates and fish, and increased algal growth rates due to eutrophication (e.g. Littler \& Littler 1984a, Hughes 1994, McCook 1999, Goreau et al. 2000, Wilkinson 2000, Szmant 2002, McManus \& Polsenberg 2004, Burkepile \& Hay 2006). However, the abundance of algae on reefs (or lack thereof) cannot always be explained by these factors alone (McCook 1999, Szmant 2002, Vroom et al. 2006, Vermeij et al. 2009a, 2010). Nutrient loading and herbivore abundance will, to a certain degree, drive the distribution and species 
composition of algal communities at every location, but other factors (e.g. seasonality, coral abundance, storms, invasive species; Williams et al. 2001, Schaffelke et al. 2006) must be considered to fully explain the abundance of macroalgae on reef communities worldwide.

A group that receives relatively little attention in studies aiming to explain the local abundance of macroalgae and corals is crustose coralline algae (CCA; Rhodophyta, Corallinaceae). CCA are capable of calcification and are potentially important components of reef communities for several reasons: (1) they were abundant on reefs before coral-macroalgal 'phase shifts' occurred (Sandin et al. 2008, Vermeij et al. 2010); (2) they dominate space not occupied by corals on undisturbed reefs (Steneck 1997, Sandin et al. 2008); (3) they are beneficial to coral recruitment as they guide settling planulae to suitable settlement locations (Morse et al. 1988, 1996, Heyward \& Negri 1999, Harrington et al. 2004, Ritson-Williams et al. 2009); (4) they are known to exude chemicals that serve as antifouling compounds (Suzuki et al. 1998, Kim et al. 2004); (5) they create refuges for microherbivores that control macroalgal overgrowth (Paine 1980, Steneck 1982); (6) they can shed their thalli to prevent macroalgal establishment (Johnson \& Mann 1986); and (7) the microtopography of the hard coralline surface can prevent macroalgal establishment by exposing germlings to mechanical dislodgement (Figueiredo et al. 1997). In summary, CCA can play an important role during the earliest life stages of both corals (positive) and macroalgae (negative).

Macroalgae colonize free space by releasing sexual propagules ('spores') (Airoldi 2000, Maggs \& Callow 2003) that are often produced in enormous quantities (e.g. $5.3 \times 10^{5}$ zoospores plant ${ }^{-1} \mathrm{~d}^{-1}$; Maggs \& Callow 2003). Algae can also use asexually generated fragments to occupy new space (e.g. Smith et al. 2002, Vermeij et al. 2009b). Observations from marine systems other than coral reefs show that the earliest life stages of macroalgae have greater sensitivity and different reactivity towards factors such as temperature, light, herbivory, and nutrients than adult stages (Lotze 1998, Lotze et al. 1999, 2000). Some macroalgae allocate between 4 and $50 \%$ of their annual biomass production to reproductive output (Maggs \& Callow 2003). The recruitment potential for macroalgae is thus enormous - should germlings escape natural survival bottlenecks such as herbivory, spatial competition, and nutrient limitation.

First, we determined whether the presence of established macroalgae decreases with increasing cover by CCA on shallow-water reef systems on Maui (Hawaii, USA). Second, we experimentally investigated whether CCA are capable of suppressing spore germination of macroalgae using the green alga Ulva fasciata.
Our work builds on the idea that CCA are an undervalued functional group that could help maintain coral dominance on reef communities. The beneficial effect of certain CCA on coral recruitment has been widely documented (e.g. Morse et al. 1988, 1996, Heyward \& Negri 1999, Harrington et al. 2004), but the suite of ecological functions that CCA provide to the wider reef community is less appreciated. If CCA negatively affect recruitment and growth of nearby and alreadyestablished macroalgae, they would indirectly contribute to the maintenance of coral-dominated reef communities.

\section{MATERIALS AND METHODS}

Study system and species. All experiments were carried out on the island of Maui between March and April 2008. Plants used for laboratory experiments were collected at Kahekili $\left(20^{\circ} 56^{\prime} 12^{\prime \prime} \mathrm{N}, 156^{\circ} 41^{\prime} 35^{\prime \prime} \mathrm{W}\right)$, where the green macroalga Ulva fasciata Delile 1813 (aka 'sea lettuce') is abundant at depths of 0 to $2 \mathrm{~m}$. $U$. fasciata is locally very abundant in shallow-water reef systems on Hawaii where it is considered a 'nuisance species'. Its presence often indicates freshwater input or pollution (Magruder \& Hunt 1979). For more information on $U$. fasciata, see www.algaebase.org. The species is a very suitable candidate for studies of early life history in macroalgae, as release of spores can be induced with increases in nutrients above normal levels (Nordby 1977). Rubble pieces covered by multispecific communities of CCA (mainly Porolithon spp. and Hydrolithon spp.) were also collected at Kahekili. All collected plants were transported $(<20 \mathrm{~min})$ to the University of Hawaii's field laboratory in Lahaina (Maui) where they were used in laboratory experiments.

Benthic surveys. Benthic community composition was quantified from photoquadrats $(0.50 \mathrm{~m} \times 0.50 \mathrm{~m})$ taken using high-resolution digital photography at 30 random points along the $5 \mathrm{~m}$ isobath at each of 10 sites along the northwestern shore of Maui (see Vermeij et al. 2010 for survey methods and locations). The total surface area of CCA and macroalgae was measured in Adobe Photoshop (v. 8.0, Adobe Systems) and expressed as a percentage of the total area of the photoquadrat. Macroalgae are defined as erect, fleshy algae larger than $2 \mathrm{~cm}$ in height.

Experimental procedures. At the beginning of our experiment, small sections of collected Ulva fasciata plants were broken off to generate fragments, each weighing $0.25 \mathrm{~g}$ (after spinning them to constant weight in a salad spinner). Each fragment was generated from a separate individual. Fragments were subjected to different experimental treatments (see next paragraph) and weighed using the same method after 
$4 \mathrm{~d}$ (precision: $0.001 \mathrm{~g}$ ). Experiments were performed in indoor, closed aquarium systems, where each fragment was kept in a separate 11 aerated glass container. Water temperature and light levels were kept similar to those observed in the field during the same period (25 to $26^{\circ} \mathrm{C}$ and $30 \%$ of full sunlight; see Vermeij et al. $2009 \mathrm{~b}$ for details on the experimental setup).

Fragments of Ulva fasciata $\left(\mathrm{n}=20\right.$ treatment $^{-1}$ ) were allocated to 1 of 4 experimental treatments: with $\left(\mathrm{N}^{+}\right)$ or without nutrients $\left(\mathrm{N}^{-}\right)$cross-factored with CCA presence $\left(\mathrm{CCA}^{+}\right)$or absence $\left(\mathrm{CCA}^{-}\right)$. Nutrient additions to induce spore release (De Boer 1981) were made by dissolving ammonium chloride $\left(\mathrm{NH}_{4} \mathrm{Cl}\right)$ and potassium phosphate $\left(\mathrm{K}_{2} \mathrm{PO}_{4}\right)$ in filtered ambient seawater. The nutrient solution was added to the containers holding the algal fragments to achieve a final concentration of $+3.0 \mu \mathrm{mol} \mathrm{PO}_{4}$ and $+30.0 \mu \mathrm{mol} \mathrm{NH}_{4}$ above levels in ambient seawater. All seawater in the present study was filtered $(0.1 \mu \mathrm{m})$ before use and refreshed at 2 d intervals to maintain a continuous supply of nutrients.

Rubble covered with crustose coralline was checked for other organisms that could confound the outcome of the experiment (e.g. worms, turf algae) and only rubble covered exclusively (i.e. $100 \%$ ) by CCA was used in the experiments. One piece of rubble measuring approximately $4 \times 2 \times 1 \mathrm{~cm}$ was added to each experimental container. Pieces of rubble scrubbed free of all epibiota with a steel brush were used as a control in treatments without CCA. Scrubbing occurred 5 to $7 \mathrm{~d}$ before the start of the experiment to minimize the negative effects of potentially damaged organisms present in the rubble on the water quality. Growth, spore release, and spore recruitment success were quantified for 20 algal fragments treatment ${ }^{-1}$ (i.e. $\mathrm{N}^{-} \mathrm{CCA}^{-}$, $\mathrm{N}^{-} \mathrm{CCA}^{+}, \mathrm{N}^{+} \mathrm{CCA}^{-}, \mathrm{N}^{+} \mathrm{CCA}^{+}$). Fragment growth was calculated as the relative growth rate (RGR) using the following formula:

$$
\mathrm{RGR}=\frac{\ln \left(W_{T_{0}+\Delta T}\right)-\ln \left(W_{T_{0}}\right)}{\left(T_{0+\Delta T}\right)-T_{0}}
$$

where $W$ is the plant's weight in grams, $T$ is time in days, and $\Delta T$ is $4 \mathrm{~d}$. Spawning in Ulva fasciata is easily recognized, as the outer edges of its thalli become transparent after spore release. Released spores always formed a thin, but clearly visible green layer at the bottom of the experimental container. The presence of released spores was confirmed through inspection of the container walls, water, and rubble with a BW-1 fluorescence dive light (Nightsea), as the spores' red fluorescence could easily be detected through a yellow filter. Recruitment success was measured as the number of viable $U$. fasciata spores that attached to the bottom of the experimental container, i.e. as percentage bottom cover. A digital photograph was taken from above and the percentage of the bottom covered by $U$. fasciata spores was determined in Adobe Photoshop.

Statistical analyses. The possible negative relationship between the occurrence of macroalgae and the abundance of CCA was analyzed using logistic regression. This approach was chosen to correct for the inherent negative relationship that exists between the relative abundance of 2 groups of organisms cooccurring within a fixed space such as a quadrat. We looked at the probability that macroalgae were simply present (1) or absent (0) (i.e. without explicit reference to the amount of macroalgae present) in response to increased abundance of CCA.

The effect of the 4 experimental treatments on fragment growth rates was analyzed using factorial ANOVA. A factorial ANOVA was also used to determine if the coverage of recruited spores differed among the 4 treatments. Significant interaction terms between nutrient and time were analyzed using post hoc analyses (Tukey HSD) after making Bonferroni corrections to the p-values as described by Rice (1989). Differences in the mean number of individuals that spawned in the different treatments were compared using a $Z$-test for proportions because the response variable (spawning) was a binary variable (plants either spawned or not). Effective sample sizes for all experiments were determined using power analyses in preliminary experiments.

\section{RESULTS}

In the field, increased abundance of CCA lowered the probability that macroalgae were present within the same quadrat (logit regression: $\beta_{0}=1.3904, \beta_{1}=$ $-0.1316, \chi^{2}=24.622$, df $\left.=1, p<0.0001\right)$. The relationship between the abundance of CCA and the abundance of macroalgae and the logistic-regression relationship showing the probability that macroalgae are present as a function of the abundance of CCA are shown in Fig. 1. Macroalgae that could not be identified to species level from the pictures were simply classified as 'macroalgae'. Macroalgae that could be identified were mostly Derbesia spp. (17.4\% of total), Acanthophora spp. (10.9\%), Halimeda spp. (7.3\%), and Amencia spp. (4.9\%). Ulva fasciata comprised $3.2 \%$ of the total macroalgal cover when all sites were pooled.

In the experiment with Ulva fasciata, the presence of CCA significantly reduced algal relative growth rates with respect to controls (Table 1). Relative growth rates of $U$. fasciata increased by $54.6 \%$ when CCA were absent (Fig. 2). Nutrient additions had no significant effect on relative growth rates (Table 1). Within the context of our experimental setting, relative growth 


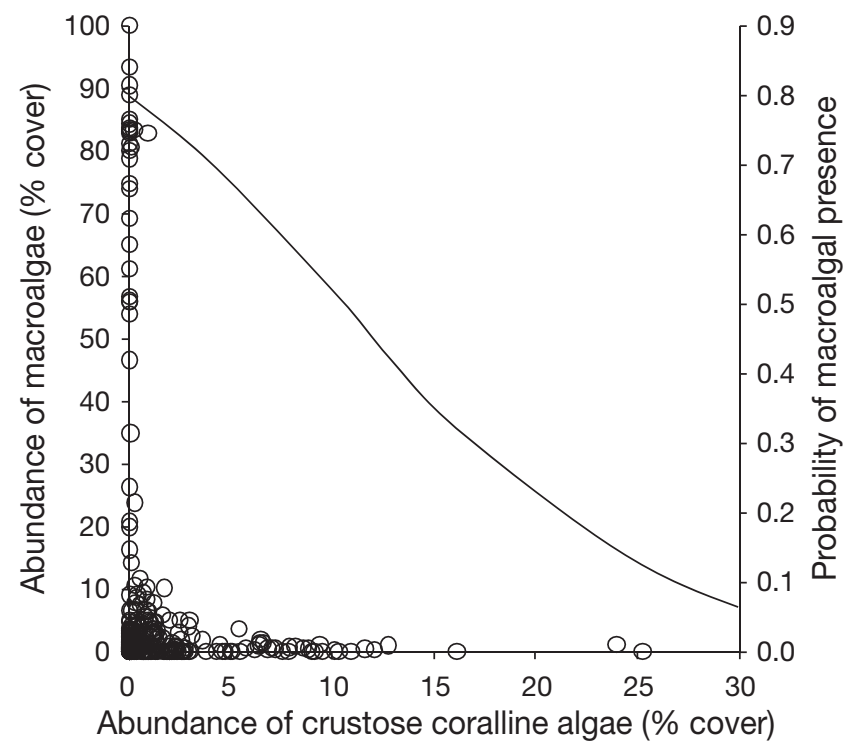

Fig. 1. Relationship between crustose coralline algae abundance and macroalgae abundance (left axis) as measured in 50 $\times 50 \mathrm{~cm}$ quadrats $(\mathrm{n}=300)$ at $5 \mathrm{~m}$ depth along the northwestern shore of Maui, and the logistic regression line $\left(y=\mathrm{e}^{1.39-0.13 x} / 1+\right.$ $\mathrm{e}^{1.39-0.13 \mathrm{x}}, \mathrm{p}<0.0001$ ) showing the decreasing probability that macroalgae are present within a quadrat (right axis) as crustose coralline algal abundance increases

Table 1. Ulva fasciata. ANOVA showing the direct and interactive effects between nutrient treatment and presence of crustose coralline algae (CCA) on relative growth rates of U. fasciata

\begin{tabular}{|lcccr|}
\hline & df & MS & $F$ & \multicolumn{1}{c|}{ p } \\
\hline Nutrients & 1 & 0.228 & 1.631 & 0.21 \\
CCA & 1 & 1.003 & 7.195 & $<0.01$ \\
Nutrients $\times$ CCA & 1 & 0.017 & 0.123 & 0.73 \\
Error & 73 & 0.139 & & \\
\hline
\end{tabular}

rates of $U$. fasciata were thus significantly affected by the presence of CCA but not by nutrient additions.

Nutrient additions and the presence of CCA both induced spore release in 65 to $89 \%$ of Ulva fasciata individuals. Plants in all treatments released more spores relative to the control (i.e. without CCA and without added nutrients) (Fig. 3). There was no difference in the proportion of individuals that spawned in each treatment other than the control $(Z<1.43, \mathrm{p}>$ $0.05)$, from which they all differed significantly $(Z>$ $3.17, \mathrm{p}<0.05)$.

Recruitment of viable spores was observed in all treatments, but the highest recruitment occurred when nutrients were added and CCA were absent (Fig. 4, Table 2). While plants released spores in all treatments, only a small number recruited when CCA were

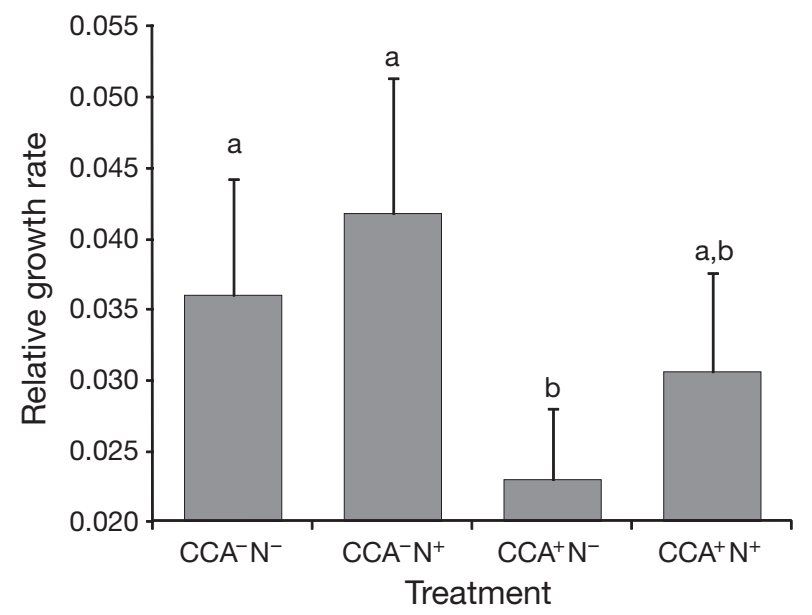

Fig. 2. Ulva fasciata. Mean relative growth rates for U. fasciata fragments grown under different experimental conditions over a $4 \mathrm{~d}$ period. Treatments are with $\left(\mathrm{N}^{+}\right)$or without nutrients $\left(\mathrm{N}^{-}\right)$, cross-factored with crustose coralline algae presence $\left(\mathrm{CCA}^{+}\right)$or absence $\left(\mathrm{CCA}^{-}\right)$. Letters above the bars indicate significant groupings based on post hoc analyses (Tukey). Error bars represent SE

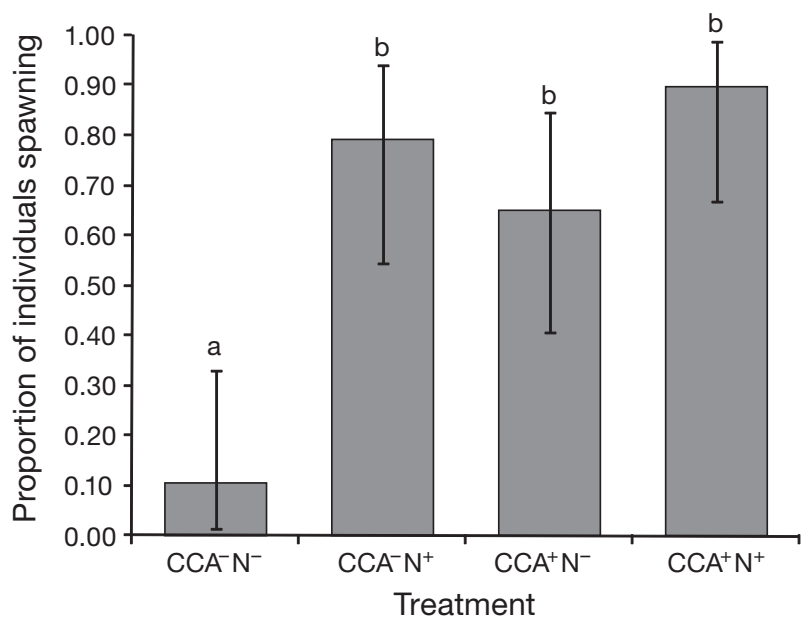

Fig. 3. Ulva fasciata. Mean proportion of $U$. fasciata fragments that spawned under different experimental conditions over a $4 \mathrm{~d}$ period. Treatments are with $\left(\mathrm{N}^{+}\right)$or without nutrients $\left(\mathrm{N}^{-}\right)$, cross-factored with crustose coralline algae presence $\left(\mathrm{CCA}^{+}\right)$ or absence $\left(\mathrm{CCA}^{-}\right)$. Letters above the bars indicate significant groupings ( $p>0.05$ ) based on a $Z$-test for proportions. Error bars represent $95 \%$ CI

present (Fig. 4). Microscopic examination of the water column and the rubble on which the CCA occurred revealed that spores were absent in both of these potential habitats. Hence, despite the fact that spore release in Ulva fasciata occurs when CCA are present, the presence of the latter subsequently reduces the recruitment success of this macroalga. 


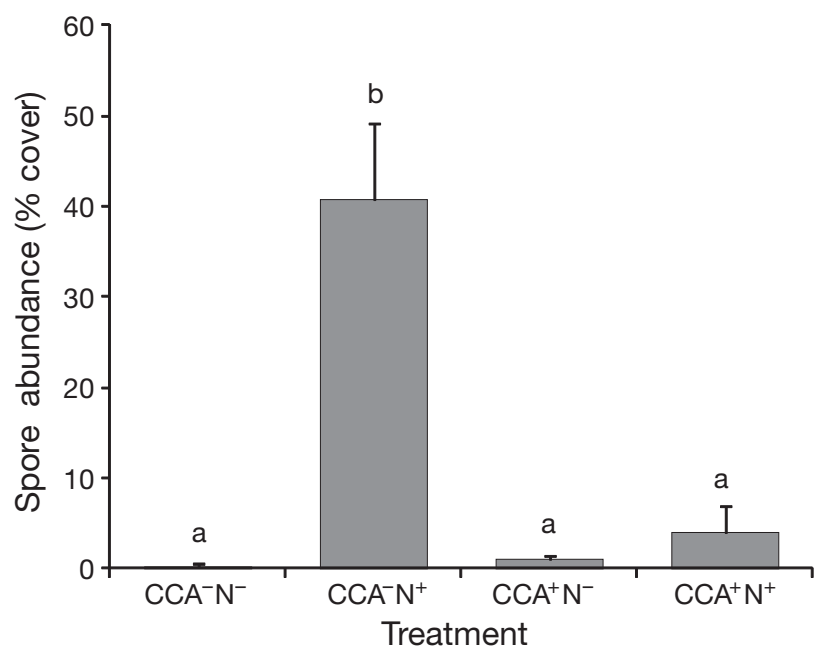

Fig. 4. Ulva fasciata. Recruitment success of U. fasciata fragments measured as the mean percentage of the bottom covered by spores after $4 \mathrm{~d}$. Treatments are with $\left(\mathrm{N}^{+}\right)$or without nutrients $\left(\mathrm{N}^{-}\right)$, cross-factored with crustose coralline algae presence $\left(\mathrm{CCA}^{+}\right)$or absence $\left(\mathrm{CCA}^{-}\right)$. Letters above the bars indicate significant groupings based on a non-parametric Kruskal-Wallis ANOVA. Error bars represent SE

\section{DISCUSSION}

In a simple experiment, we showed that mixed communities of CCA are capable of effectively reducing growth and recruitment success of the green alga Ulva fasciata. In our experiment, crustose coralline communities were dominated by Porolithon spp. and Hydrolithon spp., 2 common Hawaiian CCA. This experimental finding supports field observations in which increased abundance of CCA corresponds to a reduced probability of macroalgae occurring within the same quadrat (Fig. 1). Mixed communities of CCA therefore appear to serve as yet another biotic factor capable of limiting the local abundance of macroalgae in addition to corals, herbivorous fishes, and herbivorous invertebrates (e.g. Williams et al. 2001, Mumby 2006, Mumby et al. 2006, Sandin et al. 2008). While the limited scope of our experiments prevents broad generalizations, our results help to illustrate the potential importance of CCA as a factor that helps to maintain low macroalgal abundance on Hawaiian coral reefs, especially when coral cover is low. The observation that CCA negatively affect various life-history aspects of macroalgae has also been found in temperate marine systems (Suzuki et al. 1998, Kim et al. 2004, Daleo et al. 2006). Although by no means a comprehensive test, our results support previous studies in temperate ecosystems showing that CCA are capable of decreasing both macroalgal growth and recruitment success. Coralline algal species can prevent overgrowth by macroalgae through the production of antifouling
Table 2. Ulva fasciata. ANOVA showing the direct and interactive effects between nutrient treatment and presence of crustose coralline algae (CCA) on recruitment success of U. fasciata

\begin{tabular}{|lcccc|}
\hline & df & MS & $F$ & $p$ \\
\hline Nutrients & 1 & 9112.98 & 23.645 & $<0.001$ \\
CCA & 1 & 6215.71 & 16.127 & $<0.001$ \\
Nutrients $\times$ CCA & 1 & 6811.79 & 17.674 & $<0.001$ \\
Error & 73 & 385.41 & & \\
\hline
\end{tabular}

compounds (Suzuki et al. 1998, Kim et al. 2004), by creating refuges for herbivores that control epiphytes (Paine 1980, Steneck 1982, Karez et al. 2004), and by thallus shedding (Johnson \& Mann 1986, Keats et al. 1997). Because (micro)herbivores and thallus-shedding were not observed during the short duration of our experiment, the release of antifouling compounds is the most likely mechanism by which CCA prevented successful recruitment of macroalgal spores (Fig. 4). Biochemicals produced by CCA therefore appear to negatively affect macroalgae (with which they compete for space) in addition to positively affecting coral recruitment. Biochemicals (morphogens) associated with certain CCA species induce settlement and metamorphosis in a large number of scleractinian corals (Morse et al. 1988, 1996, Heyward \& Negri 1999, Harrington et al. 2004). Hence, CCA have the capacity to structure coral reef communities through both suppression of macroalgae and promotion of coral recruitment, 2 characteristics generally associated with 'healthy' reefs. Because CCA also help to create a stable reef substrate by cementing together sand, dead coral, and debris, especially in shallow water (Adey 1998, Diaz-Pulido et al. 2007, but see MacIntyre 1997), their importance within the wider reef community is multifaceted.

CCA are a prominent element of 'healthy' reef communities (e.g. Sandin et al. 2008), including those in Hawaii (Vermeij et al. 2010). CCA occupy most of the remaining open space on Hawaiian reefs with low coral cover. If a reef then suffers from human disturbance (e.g. overfishing, pollution, increased sedimentation), fleshy algae become the most dominant benthic organisms, whereas the abundance of CCA decreases (Vermeij et al. 2010). The decreased abundance of CCA is correlated with chronic human disturbances on coral reefs worldwide (e.g. eutrophication: Littler \& Littler 1984b, Björk et al. 1995, Belliveau \& Paul 2002; sedimentation: Fabricius \& De'ath 2001, Fabricius 2005; overfishing: Littler \& Littler 1984a,b, Steneck 1997). While many of these human disturbances favor macroalgae (e.g. eutrophication, overfishing) or weaken corals (e.g. by sedimentation) directly, 
their effect on CCA provides a secondary, indirect route by which these disturbances can be beneficial or detrimental to macroalgae and corals respectively. CCA could therefore act as 'ecological mediators' of coral-macroalgae competition, whereby the outcome of such interaction is partially influenced by the local abundance and species composition of local crustose coralline communities.

Species-specific effects were not considered in our study, as we used communities consisting of various crustose coralline species in our experiments. Different CCA species affected macroalgal growth differently in a Brazilian coastal system (Villas Boas \& Figueiredo 2004), and are known to have species-specific effects on coral recruitment (Harrington et al. 2004). Furthermore, CCA species have potentially beneficial effects on macroalgal growth in some ecological situations (Diaz-Pulido \& McCook 2004). All these observations warn against making the generalization that the presence of CCA per se is detrimental for macroalgal growth. Nevertheless, the present study clearly illustrates the potential importance of CCA in mediating coral-algae competition in a coral reef setting in Hawaii.

To the best of our knowledge, this is the first time the ability of CCA to suppress macroalgal growth has been proposed for tropical reef communities. This builds on similar observations from temperate marine systems (e.g. Suzuki et al. 1998, Kim et al. 2004, Villas Boas \& Figueiredo 2004). Because CCA are also important during the earliest life-history stages of corals (e.g. Morse et al. 1996, Heyward \& Negri 1999, Harrington et al. 2004, Vermeij \& Sandin 2008), the abundance and species composition of this functional group may influence the future abundance of macroalgae and corals, thereby affecting the commonly measured benthic organisms thought to represent degraded and healthy reefs respectively.

Acknowledgments. This research was supported by grant no. NA03NOS4780020 to C.M.S. from the Center for Sponsored Coastal Ocean Research, National Ocean Service, NOAA. K. Marhaver provided valuable comments that greatly improved an early version of this paper. This is ECOHAB publication \#325.

\section{LITERATURE CITED}

Adey WH (1998) Coral reefs: algal structured and mediated ecosystems in shallow, turbulent, alkaline waters. J Phycol 34:393-406

Airoldi L (2000) Effects of disturbance, life histories, and overgrowth on coexistence of algal crusts and turfs. Ecology 81:798-814

Belliveau SA, Paul VJ (2002) Effects of herbivory and nutrients on the early colonization of crustose coralline and fleshy algae. Mar Ecol Prog Ser 232:105-114

Björk M, Mohammed SM, Björklund M, Semesi A (1995)
Coralline algae, important coral-reef builders threatened by pollution. Ambio 24:502-505

Burkepile DE, Hay ME (2006) Herbivore vs. nutrient control of marine primary producers: context-dependent effects. Ecology 87:3128-3139

> Daleo P, Escapa M, Alberti J, Iribarne O (2006) Negative effects of an autogenic ecosystem engineer: interactions between coralline turf and an ephemeral green alga. Mar Ecol Prog Ser 315:67-73

DeBoer JA (1981) Nutrients. In: Lobban CS, Wynne MJ (eds) The biology of seawater. University of California Press, Berkeley, CA, p 356-392

Diaz-Pulido G, McCook LJ (2004) Effects of live coral, epilithic algal communities and substrate type on algal recruitment. Coral Reefs 23:225-233

Diaz-Pulido G, McCook LJ, Larkum AWD, Lotze HK and others (2007) Chapter 7. Vulnerability of macroalgae of the Great Barrier Reef to climate change. In: Johnson JE, Marshall PA (eds) Climate change and the Great Barrier Reef: a vulnerability assessment. Great Barrier Reef Marine Park Authority and the Australian Greenhouse Office, Department of the Environment and Water Resources, Townsville, p 151-192

Fabricius KE (2005) Effects of terrestrial runoff on the ecology of corals and coral reefs: review and synthesis. Mar Pollut Bull 50:125-146

Fabricius K, De'ath G (2001) Environmental factors associated with the spatial distribution of crustose coralline algae on the Great Barrier Reef. Coral Reefs 19:303-309

Figueiredo MAO, Norton TA, Kain JM (1997) Settlement and survival of epiphytes on two intertidal crustose coralline alga. J Exp Mar Biol Ecol 213:247-260

Goreau T, McClanahan T, Hayes R, Strong A (2000) Conservation of coral reefs after the 1998 global bleaching event. Conserv Biol 14:5-15

> Harrington LM, Fabricius K, Dea'th G, Negri AP (2004) Habitat selection of settlement substrata determines postsettlement survival in corals. Ecology 85:3428-3437

> Heyward AJ, Negri AP (1999) Natural inducers for coral larval metamorphosis. Coral Reefs 18:273-279

> Hughes TP (1994) Catastrophes, phase shifts, and large-scale degradation of a Caribbean coral reef. Science 265: $1547-1551$

Johnson CR, Mann KH (1986) The crustose coralline alga, Phymatolithon Foslie, inhibits the overgrowth of seaweeds without relying on herbivores. J Exp Mar Biol Ecol 96: $127-146$

Karez R, Engelbert S, Kraufuelin P, Pedersen MF, Sommer J (2004) Biomass response and changes in composition of ephemeral macroalgal assemblages along an experimental gradient of nutrient enrichment. Aquat Bot 78:103-117

> Keats DW, Knight MA, Pueschel CM (1997) Antifouling effects of epithallial shedding in three crustose coralline algae (Rhodophyta, Corallinales) on a coral reef. J Exp Mar Biol Ecol 213:281-293

> Kim MJ, Choi JC, Kang SE, Cho JY, Jin HJ, Chun BS, Hong YK (2004) Multiple allelopathic activity of the crustose coralline alga Lithophyllum yessoense against settlement and germination of seaweed spores. J Appl Phycol 16: 175-179

Littler MM, Littler DS (1984a) A relative-dominance model for biotic reefs. Proc Joint Meet Atl Reef Comm and Int Soc Reef Stud Proc Joint Meet Atl Reef Comm and Int Soc Reef Stud, p 1-2

Littler MM, Littler DS (1984b) Models of tropical reef biogenesis: the contribution of algae. Prog Phycol Res 3:322-365

Lotze HK (1998) Population dynamics and species interactions 
in macroalgal blooms, abiotic versus biotic control at different life-cycle stages. PhD thesis, Christian Albrecht Universität, Kiel

Lotze HK, Schramm W, Schories D, Worm B (1999) Control of macroalgal blooms at early developmental stages: Pilayella littoralis versus Enteromorpha spp. Oecologia 119: 46-54

Lotze HK, Worm B, Sommer U (2000) Propagule banks, herbivory and nutrient supply control population development and dominance patterns in macroalgal blooms. Oikos 89:46-58

MacIntyre IG (1997) Reevaluating the role of crustose algae in the construction of coral reefs. Proc 8th Int Coral Reef Symp, Panama 1:725-730

Maggs CA, Callow ME (2003) Algal spores, version 1.0. In: Encyclopedia of life sciences. Nature Publishing Group, London, $\mathrm{p}$ 1-6

Magruder WH, Hunt JW (1979) Seaweeds of Hawai'i. Oriental Publishing Company, Honolulu, HI

McCook LJ (1999) Macroalgae, nutrients and phase shifts on coral reefs: scientific issues and management consequences for the Great Barrier Reef. Coral Reefs 18:357-367

McManus JW, Polsenberg JF (2004) Coral-algal phase shifts on coral reefs: ecological and environmental aspects. Prog Oceanogr 60:263-279

Morse DE, Hooker N, Morse ANC, Jensen RA (1988) Control of larval metamorphosis and recruitment in sympatric agariciid corals. J Exp Mar Biol Ecol 116:193-217

Morse ANC, Iwao K, Baba M, Shimoike K, Hayashibara T, Omori M (1996) An ancient chemosensory mechanism brings new life to coral reefs. Biol Bull (Woods Hole) 191: 149-154

Mumby PJ (2006) The impact of exploiting grazers (Scaridae) on the dynamics of Caribbean coral reefs. Ecol Appl 16: 747-769

Mumby PJ, Hedley JD, Żychaluk K, Harborne AR, Blackwell PG (2006) The spatial ecology of Caribbean coral reefs: revisiting the catastrophic die-off of the urchin Diadema antillarum. Ecol Modell 196:131-148

Nordby Ø (1977) Optimal conditions for meiotic spore formation in Ulva mutabilis Føyn. Bot Mar 20:19-28

Paine RT (1980) Food webs: linkage, interaction strength and community infrastructure. J Anim Ecol 49:667-685

Rice WR (1989) Analyzing tables of statistical tests. Evolution 43:223-225

Ritson-Williams R, Arnold SN, Fogarty ND, Steneck RS, Vermeij MJA, Paul VJ (2009) New perspectives on ecological mechanisms affecting coral recruitment on reefs. Smithson Contrib Mar Sci 38:437-457

Sandin SA, Smith JE, DeMartini EE, Dinsdale EA and others

Editorial responsibility: Lisandro Benedetti-Cecchi, Pisa, Italy
(2008) Baselines and degradation of coral reefs in the Northern Line Islands. PLoS ONE 3:e1548 doi:10.1371/ journal.pone.0001548

Schaffelke B, Smith JE, Hewitt CL (2006) Introduced macroalgae: a growing concern. J Appl Phycol 18:529-541

Smith JE, Hunter CL, Smith CM (2002) Factors influencing algal blooms on tropical reefs with an emphasis on herbivory, nutrients and invasive species. Pac Sci 56:299-315

Steneck RS (1982) A limpet-coralline alga association: adaptations and defenses between a selective herbivore and its prey. Ecology 63:507-522

Steneck RS (1997) Crustose corallines, other algal functional groups, herbivores and sediments: complex interactions along reef productivity gradients. Proc 8th Int Coral Reef Symp, Panama 1:695-700

Suzuki Y, Takabayashi T, Kawaguchi T, Matsunaga K (1998) Isolation of an allelopathic substance from the crustose coralline algae, Lithophyllum spp., and its effect on the brown alga, Laminaria religiosa Miyabe (Phaeophyta). J Exp Mar Biol Ecol 225:69-77

Szmant AM (2002) Nutrient enrichment on coral reefs: Is it a major cause of coral reef decline? Estuaries 25:743-766

Vermeij MJA, Sandin SA (2008) Density-dependent settlement and mortality structure the earliest life phases of a coral population. Ecology 89:1994-2004

Vermeij MJA, Smith TB, Dailer ML, Smith CM (2009a) Release from native herbivores facilitates the persistence of invasive marine algae: a biogeographical comparison of the relative contribution of nutrients and herbivory to invasion success. Biol Invasions 11:1463-1474

> Vermeij MJA, Dailer ML, Smith CM (2009b) Nutrient enrichment promotes survival and dispersal of drifting fragments in an invasive tropical macroalga. Coral Reefs 28:429-435

> Vermeij MJA, Dailer ML, Walsh SM, Donovan MK, Smith CM (2010) The effects of trophic interactions and spatial competition on algal community composition on Hawaiian coral reefs. PSZN I: Mar Ecol 31:291-299

Villas Boas AB, Figueiredo MAO (2004) Are anti-fouling effects in coralline algae species specific? Braz J Oceanogr 52:11-18

Vroom PS, Page KN, Kenyon JC, Brainard RE (2006) Algaedominated reefs: numerous reports suggest that reefs must be dominated by coral to be healthy, but many thriving reefs depend more on algae. Am Sci 94:430-438

Wilkinson CR (2000) Status of coral reefs of the world. Australian Institute of Marine Science, Townsville

Williams ID, Polunin NVC, Hendrick VJ (2001) Limits to grazing by herbivorous fishes and the impact of low coral cover on macroalgal abundance on a coral reef in Belize. Mar Ecol Prog Ser 222:187-196

Submitted: July 13, 2010; Accepted: November 29, 2010

Proofs received from author(s): January 12, 2011 